\title{
Prevalence and associated factors of neurodevelopmental disability among infants in eastern Uganda: a population based study
}

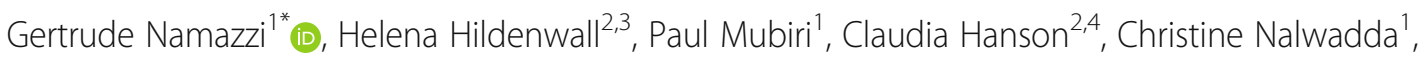
Margaret Nampijja ${ }^{5}$, Angelina Kakooza-Mwesige ${ }^{6}$, Peter Waiswa ${ }^{1}$ and James K. Tumwine ${ }^{6}$

\begin{abstract}
Background: Neurodevelopmental disability (NDD) is increasingly acknowledged as one of the important causes of disease burden in low income countries. None the less, there is a dearth of data on the burden of NDD and its determinants in these settings. We aimed to establish the prevalence and factors associated with NDD among infants in Eastern Uganda.

Methods: We assessed 487 infants aged 9-12 months within Iganga-Mayuge Health Demographic Surveillance Site in Eastern Uganda using the Malawi Developmental Assessment Tool. The tool has four domains: gross motor, fine motor, language and social domains. An infant failed a domain if she/he failed more than two parameters of the expected at his/her age.

We interviewed mothers on factors that could influence the infants' neurodevelopmental outcomes. Data were analysed using STATA version 14 . We used odds ratios and $95 \%$ confidence intervals to assess statistical significance of associations.

Results: Of the 487 infants, 62(12.7\%) had an NDD in at least one of the domains. The most affected was social behaviour where 52(10.7\%) infants had an NDD. Severe impairment was seen among 9(1.8\%) infants with NDD in either three or four domains.

Factors associated with NDD at multivariate logistic regression included: parity of more than three children (aOR $=$ $1.8,95 \% \mathrm{Cl}: 1.02-3.18)$; failure to cry at birth $(\mathrm{aOR}=3.6,95 \% \mathrm{Cl}: 1.46-9.17)$ and post-neonatal complications (aOR $=$ 4.15, 95\% Cl: 1.22-14.10). Low birth weight, immediate and exclusive breast feeding were not significantly associated with NDD.

Conclusion: We found a high NDD burden among infants particularly in the social behaviour domain. To optimise the socio-neural development of infants, programs are needed to educate and work with families on how to engage and stimulate infants. Existing immunisation clinics and community health worker strategies provide an excellent opportunity for stemming this burden.
\end{abstract}

Keywords: Neurodevelopmental disability, Prevalence and associated factors, Infants, Eastern Uganda

\footnotetext{
* Correspondence: namazzi_ge@yahoo.co.uk

${ }^{1}$ Makerere University School of Public Health, College of Health Sciences,

Mulago Hill Road, P. O. Box, 7072 Kampala, Uganda

Full list of author information is available at the end of the article
}

(c) The Author(s). 2019 Open Access This article is distributed under the terms of the Creative Commons Attribution 4.0 International License (http://creativecommons.org/licenses/by/4.0/), which permits unrestricted use, distribution, and reproduction in any medium, provided you give appropriate credit to the original author(s) and the source, provide a link to the Creative Commons license, and indicate if changes were made. The Creative Commons Public Domain Dedication waiver (http://creativecommons.org/publicdomain/zero/1.0/) applies to the data made available in this article, unless otherwise stated. 


\section{Introduction}

Globally, for the past decade there have been significant strides to curb neonatal and infant mortality, albeit with an increased risk of neurodevelopmental disabilities (NDD) [1-3]. More than $80 \%$ of these disabilities are in low and middle income countries (LMIC) [4,5] where $90 \%$ of the world's children live [6]. None the less, there is paucity of accurate data characterising developmental disability in these settings. The NDD include deficiencies in motor functions, socio-emotional behaviour, sensory function, attention, memory and language during the early period of a child's growth [7]. These may result in profound limitations in learning and realising full developmental potential with subsequent constraints in social and economic development of communities and nations at large [4, 5].

According to the bio-ecological systems theory of early child development, biological and environmental risk factors have a complex interaction that may result in NDD [8]. The environmental risk factors include: limited social interactions, poverty, and one's surroundings [9]. Socio-emotional development of children is shaped by family relationships and parental practices [10]. Children learn by observing those around them and through social referencing. Loving and positive relationships coupled with active stimulation and encouragement result in an environment that builds confidence of the child in his/her ability to communicate and relate with others. However, these relationships may be compromised by the number of children in the family $[11,12]$.

Biological risk factors on the other hand, comprise of insults to the unborn baby, including poor health status and nutritional deficiencies during the prenatal period, child birth, infancy and early childhood [9].

There is consistent evidence showing that newborn babies suffering from conditions such as sepsis/infections, asphyxia (defined as failure to cry at birth at community level), premature birth, low birth weight and pathological jaundice have a higher likelihood of NDD [2, 13-15]. This risk may be compounded by the three delays in seeking care: delay in making a decision due to ignorance and cultural practices; delay in reaching the health facilities and delay in receiving quality care at health facilities due to supply side challenges [16].

In Uganda, more than a quarter of births occur at home or with the aid of unskilled traditional birth attendants who are not considered effective to reduce the burden of ill-health but pose a higher risk of intrapartum complications and resultant NDD $[17,18]$. The situation is worse in rural areas with delays in identification, management and follow up care of vulnerable infants in the neonatal and the post-neonatal period. In addition, mothers may not seek care for their sick infants from health facilities due to limited physical access to care or because of cultural beliefs and use of traditional remedies. While the use of Community Health Workers (CHWs), locally known as Village Health Teams (VHTs), is wide spread in the country, utilization of child health services is still limited with potential negative consequences on child development [19].

The Uganda national policy framework on early child development gives guidance for access to quality services for all children from conception to eight years. These services include education, nutrition, child protection, health care, family and community support and empowerment. Despite the existence of this policy framework, implementation of some essential interventions is still inadequate [20]. For instance programmes that engage, and empower families and communities to foster early child stimulation and development are limited. This might be due to lack of national statistics on the burden, pattern and risk factors of early child NDD.

To inform policies and programming for appropriate responses and actions in the country and areas with similar settings, this study aimed at assessing the prevalence of NDD and associated factors among infants aged nine to twelve months of age in a health demographic site in Eastern Uganda. This study focused on health care factors that can potentially influence neurodevelopmental outcomes during pregnancy, child birth, neonatal and the post-neonatal period. In addition, we also assessed the demographic and socio-economic factors of the parents.

\section{Methods}

\section{Study area and design}

We conducted a cross-sectional study in December 2017 in the Iganga/Mayuge Health Demographic Surveillance Site (HDSS) in Eastern Uganda. The HDSS has 65 villages with a population of about 86,000 people who are mostly (80\%) rural and practice subsistence farming. Most of the people in the study area are Basoga, the third largest ethnic tribe in Uganda. Generally, in this context, there is preference for large families, and child rearing is mostly the responsibility of the mother. However, due to the many responsibilities of women, children are usually left to play with fellow children, and parents are rarely involved in active stimulation of their children. There is also an extended family system with controlling parenting practices by multiple family members, like the rest of the country [21]. The total fertility rate is 5.4 with average annual births of around 2000 babies of whom $11 \%$ are low birth weight or preterm babies [22]. The neonatal and infant mortality rates in 2015 were 30 and $60 / 1000$ live births respectively compared to national average rates of 27 and 43/1000 live births [17]. The site is served by one general hospital which 
offers comprehensive Emergency Obstetric and Newborn Care, and 12 lower level health facilities, which offer basic maternal and newborn care services. There are, also, community health workers, who have been trained in basic maternal and newborn care and support the tracking of pregnancies and their outcomes. The site has been active since 2005 when a population baseline census was conducted and all households were given identification numbers. The site conducts bi-annual censuses using trained field assistants during which surveillance data is updated. The surveillance data includes: births, deaths, migration, and pregnancy outcomes [22].

\section{Study participants and procedures}

We used data of the surveillance round done between March and May 2017. Five hundred seventeen infants born between January and March 2017 (who were expected to be nine to twelve months in December 2017) were identified. Information captured from the surveillance round data included: the villages, household heads, and mothers' names, names of the babies and dates of birth. Household identification numbers were also recorded and used to help in physical identification of the homesteads during data collection.

We carried out neurodevelopmental assessments using the Malawi Developmental Assessment Tool (MDAT) in December 2017. The MDAT tool has four developmental domains: Gross motor, Fine motor, Language and Social behaviour. The tool was created and validated to assess neurodevelopmental outcomes of children in rural African setting from birth to six years. The validation tests of the MDAT tool indicated high sensitivity and specificity to identify NDDs of 97 and $82 \%$ respectively [23]. Similarly, the overall reliability was very good with a kappa of more than 0.75 .

In our study, the assessment involved getting a parental report, observation with a checklist, and direct administration to the child. Table 1 shows examples of the parameters that were assessed under each MDAT domain. For each parameter the child scored 1 if it was able to perform and a 0 if not. The child was assessed on several parameters in each domain until s/he failed six parameters consecutively then the assessment of that domain was stopped. An infant failed a domain if $s$ he failed more than two parameters of the expected at his/her age. The assessments were done by seven nurses who received a five day training in use of the MDAT tool.

In addition to assessment using the MDAT tool, the infants were evaluated on other neurodevelopmental parameters such as sight, hearing and whether the infant had had any convulsions. We placed a dangling object in front of an infant to assess whether he/she could track and reach out. Similarly, observations were made on whether the child could turn towards the direction of a rattling noise. In case of a history of convulsions, we ruled out any associated fevers to enable differentiation of febrile convulsions from convulsions due to neural impairment. We also measured the head circumference of infants using a tape measure, and took their body weights using Seca scales.

The mothers were interviewed on socioeconomic and demographic characteristics, and health care practices which could potentially affect the neurodevelopment of the infant such as antenatal care (ANC) attendance,

Table 1 Examples of parameters of Neuro-developmental assessment using the Malawi Developmental Assessment Tool (MDAT)

\begin{tabular}{|c|c|c|}
\hline Developmental domain & Method of assessment & Examples of items/parameters assessed \\
\hline \multirow[t]{3}{*}{ Gross motor } & Parental report & Crawls, Pulls self to stand \\
\hline & Observation & $\begin{array}{l}\text { Sits without support } \\
\text { Able to stand if holding onto things }\end{array}$ \\
\hline & Direct administration & Walks using both hands of someone \\
\hline \multirow[t]{2}{*}{ Fine motor } & Parental report & Transfers objects from one hand to another \\
\hline & Observation/direct administration & $\begin{array}{l}\text { Can use a neat pincer grasp to pick up object between thumb and fore finger } \\
\text { Puts blocks or stones in and out of a plastic tea cup in imitation }\end{array}$ \\
\hline \multirow[t]{3}{*}{ Language skills } & Parental report & $\begin{array}{l}\text { Understands when being told 'no' or being cautioned } \\
\text { Shakes head or does something to indicate No }\end{array}$ \\
\hline & Observation report & $\begin{array}{l}\text { Makes double syllable sounds, tata, dada, mama } \\
\text { Says two other words other than mama, dada, e.g. cup, cow, spoon }\end{array}$ \\
\hline & Direct administration & Follows one stage command such as 'give me the cup' \\
\hline \multirow[t]{3}{*}{ Social behaviour } & Parental report & $\begin{array}{l}\text { Helps by putting hands out to be washed } \\
\text { Indicates in some way the need for poo or pee }\end{array}$ \\
\hline & Observation & Frolics with mother/caregiver in response to being played with \\
\hline & Direct administration & $\begin{array}{l}\text { Stretches to be picked } \\
\text { Drinks from a cup by self }\end{array}$ \\
\hline
\end{tabular}


vaccination with tetanus toxoid, uptake of sulfadoxine pyrimethamine to prevent malaria, and ferrous sulphate and folic acid tablets. We also included delivery care practices (place of delivery, mode of delivery, whether there was a skilled attendant at birth or not, the gestational age (GA) at birth of the child, and birth outcome), and postnatal practices (cord care, keeping the baby warm, immediate and exclusive breastfeeding, as well as health seeking care practices for the infant). In addition, we asked for a history of post-neonatal complications defined as any danger sign (inability to feed well, convulsions, lethargy/unconsciousness, chest in-drawing and grunting, hypothermia, and high body temperature) after the neonatal period.

\section{Data management and analysis}

Data from the MDAT and on risk factors as assessed in the interviews with the mothers were processed (double entered with quality checks) using EPIDATA version 3.2 and exported to STATA version 14 for analysis.

Descriptive statistics were generated on sociodemographic characteristics, care practices of the mothers during pregnancy, delivery and postnatal period, and on weight and head circumference of the infants. We generated Z-scores for weight for age and head circumference for age using Zanthro techniques [24]. Z-scores for weight for age were used to assess the nutrition status of infants. The prevalence of NDD was generated by obtaining the percentages of infants who failed at least one of the MDAT domains. Multivariable logistic regression was conducted to identify factors associated with NDD. Variables yielding a $p$-value $=0.2$ in the univariate analysis, together with factors known a priori to be predictors of NDD (Father's occupation as proxy for socio-economic status, maternal age, maternal education, breast feeding practices, and tetanus toxoid to the mother) were included in multivariable analysis. The model was refined by backward elimination using the change in log likelihood ratio of successive models with a significance level of 0.05 . Variables were tested for collinearity by examining correlation coefficients, and if found to be related one was dropped.

\section{Results}

We assessed 487 babies out of the targeted 517 in Iganga/Mayuge HDSS. Thirty infants could not be accessed: 7 were out of the age range, 3 had died and 20 had either shifted, or were not at home on three repeated visits. Out of the 487 babies assessed 144 (29.6\%) were aged nine months, $116(23.8 \%)$ were 10 months, $126(25.9 \%)$ were 11 months, and 101 (20.7) were 12 months. The mean weight of infants at time of data collection was $8.5 \mathrm{~kg}$ (range: $4.5-12.5 \mathrm{~kg} ; \mathrm{SD}=1.1 \mathrm{~kg}$ ). The weight for age Z-scores had a normal distribution, with
5.0\% below $-2.0 \mathrm{Z}$ score. Similarly, the head circumference had a normal distribution of the $\mathrm{Z}$ scores, with a mean of $45.4 \mathrm{~cm}, \mathrm{SD}=1.4 \mathrm{~cm}$ (range: $39.0-50.3 \mathrm{~cm}$ ). There were no significant sex differences among the infants: 250 (51.3\%) were male.

We found 62 (12.7\%) infants with neurodevelopmental disability in at least one of the domains. The most affected domain was the social behaviour where 52 (10.7\%) infants had a NDD followed by the language domain with $20(4.1 \%)$ affected children. Severe impairment, defined as NDD in at least three or all the four domains, was seen in $9(1.85 \%)$ infants. Eleven (2.3\%) babies, had NDD in two domains. Gross motor and Fine motor were equally affected at $1.8 \%$ (9/487). Five babies (1.03\%) were reported to have had non-febrile convulsions. None of the babies had visual or auditory disabilities.

At bivariate analysis, socio-demographic factors independently associated with NDD included: parity of the mother of more than three children $(\mathrm{OR}=1.87,95 \% \mathrm{CI}$ : 1.09-3.21) (Table 2). Mother's age, level of education, and employment status of the father were not significantly associated with NDD. Similarly, antenatal care practices like ANC attendance, uptake of sulfadoxine pyrimethamine and ferrous sulphate/folic acid tablets to prevent malaria and anaemia respectively, were not associated with NDD (Table 3). Reported complications during pregnancy (High blood pressure, anaemia, fevers, vaginal bleeding) were also not associated with NDD. Delivering outside hospital (at home or primary level health facility) $(\mathrm{OR}=1.84, \mathrm{CI}: 1.06-3.18)$, infant failing to cry at birth $(\mathrm{OR}=3.27$, CI: $1.42-7.5)$, and experiencing post-neonatal complications $(\mathrm{OR}=3.5, \mathrm{CI}$ : 1.08 11.79) were associated with NDD (Table 3). Furthermore, if the mother reported that the infant had been ill more than three times since birth the odds of NDD increased to more than twice ( $\mathrm{OR}=2.36, \mathrm{CI}=1.28-4.38)$.

Using multivariable logistic regression, we found three factors associated with NDD. These included: parity of mother of more than three children $(\mathrm{aOR}=1.80$, CI: $1.02-3.18)$, infant failing to cry at birth $(\mathrm{aOR}=3.60$, CI: $1.46-9.17)$ and post-neonatal complications $(\mathrm{aOR}=4.15$, 95\% CI: 1.22-14.10) (Table 4).

The prevalence of Low birth weight $(<2.5 \mathrm{~kg})$ was $5 \%$ (21/417), and NDD distribution among them was not different from those who had normal weight $(p=0.190)$ (Table 3). Most (87\%) of the infants had been weighed and their birth weights were either reported by their mothers or noted from the discharge card. Of the 433 mothers who gave the LNMP, only $4(0.9 \%)$ infants had been delivered at GA less than 37 weeks. Immediate and exclusive breast feeding for at least six months were found to be almost universal, and were not significantly associated with NDD. In addition, almost all, 463(95.1\%) 
Table 2 Distribution of neurodevelopmental disability (NDD) by socio-demographic characteristics among infants in lganga-Mayuge HDSS

\begin{tabular}{|c|c|c|c|c|}
\hline Characteristic & $\begin{array}{l}\text { Infants without NDD N=425 } \\
n(\%)\end{array}$ & $\begin{array}{l}\text { Infants with NDD N=62 } \\
n(\%)\end{array}$ & $\operatorname{COR}(95 \% \mathrm{Cl})$ & $p$ value \\
\hline \multicolumn{5}{|l|}{ Socio-demographic Characteristics } \\
\hline \multicolumn{5}{|l|}{ Age of mother (years) } \\
\hline$<20$ & $52(12.2)$ & $6(9.7)$ & & \\
\hline $20-29$ & $264(62.1)$ & $38(61.3)$ & $1.25(0.50-3.10)$ & 0.763 \\
\hline $30+$ & $109(25.6)$ & $18(29)$. & $1.43(0.54-3.82)$ & \\
\hline \multicolumn{5}{|l|}{ Marital status } \\
\hline Single/separated & $52(12.2)$ & $3(4.8)$ & $2.74(0.83-9.06)$ & 0.129 \\
\hline Married & $373(87.8)$ & $59(95.2)$ & & \\
\hline \multicolumn{5}{|l|}{ Level of education of mother } \\
\hline None, Primary, or O-level secondary ( $\leq 11$ years of school) & $392(92.2)$ & $60(96.8)$ & $0.39(0.09-1.69)$ & 0.291 \\
\hline Advanced level (> 11 years of School) & $33(7.8)$ & $2(3.2)$ & & \\
\hline \multicolumn{5}{|l|}{ Employment of father } \\
\hline Salaried & $72(16.9)$ & $8(12.9)$ & & \\
\hline Business & 130 (30.6) & $29(46.8)$ & $2.01(0.87-4.62)$ & 0.040 \\
\hline Others & $223(52.5)$ & $25(40.3)$ & $1.01(0.43-2.33)$ & \\
\hline \multicolumn{5}{|l|}{ Mother's parity } \\
\hline $1-3$ & $284(66.8)$ & $32(51.6)$ & & \\
\hline $4+$ & 141 (33.2) & $30(48.4)$ & $1.88(1.10-3.23)$ & 0.019 \\
\hline
\end{tabular}

COR Crude odds ratio

mothers of the infants had received tetanus toxoid vaccination during pregnancy. Similarly, $96.5 \%$ of the infants had up-to-date immunization.

\section{Discussion}

We report a high prevalence of neurodevelopmental disabilities in the studied setting, based on the MDAT tool, in the domain of social behaviour. The key associated factors were: post-neonatal complications, failure of the infant to cry at birth or birth asphyxia, and parity of more than three children. The prevalence of $12.7 \%$ NDD among infants in this study is higher than the global prevalence of $8.4 \%$ reported in the 2016 Global Burden of Disease data [25]. Our study prevalence is also higher than that reported in a study done in Kenya [11] of $2.9 \%$, and one in Ethiopia [26] of $2.7 \%$. However, these studies involved children less than five years of age and older children whereas we focus on infants. It is known that children with severe NDD are more likely to die early in life. Other reasons for the difference could be due to the use of different assessment tools such as the Ten Question Questionnaire, while in our study we used the MDAT tool, which also involves a physical assessment of the children, hence is more likely to capture even mild to moderate cases.

Developmental disability prevalence figures for LMIC have been reported to range from as low as 0.4 to $45.2 \%$
[26-28]. The wide variation could be due to differences in health care systems, different definitions of NDD, diverse ages of children assessed, and various tools used for measurement. Thus, there is a need for standardised assessment tools and definitions of NDD. In addition, different studies focus on different domains for assessment. In the current study, we found fewer cases of severe NDD, which could be as a result of the high perinatal mortality rates in Uganda, where the very sick neonates and early preterms (who are more likely to develop severe NDD) do not survive [29].

The results of this study are different from those reported in a study conducted in 16 LICs where impairments in language were more common than in any other domains [28]. More studies have shown a variability in the functions impaired. For example in a study conducted among Ethiopian infants the commonest (71\%) disability was in the sensory (hearing) domain [26], while in the Kenyan studies it was mostly the cognitive impairment $[11,30]$. It appears therefore that these differences are a result of variations in the way NDD are measured.

With regard to NDD associated factors, our findings show that both the biological and environmental factors (as highlighted under the bio-ecological systems theory) were significantly associated with NDD. While postneonatal complications and failure of the infant to cry at 
Table 3 Distribution of neurodevelopmental disability by antenatal, delivery, and neonatal characteristics, among infants in IgangaMayuge HDSS

\begin{tabular}{|c|c|c|c|c|}
\hline Characteristics & Infants without NDD & Infants with NDD & COR $(95 \% \mathrm{Cl})$ & $p$-value \\
\hline \multicolumn{5}{|l|}{ ANC Attendance } \\
\hline $1-3$ times & $162(38.1)$ & $17(27.4)$ & $1.63(0.90-2.94)$ & 0.103 \\
\hline $4+$ & $263(61.9)$ & $45(72.6)$ & & \\
\hline \multicolumn{5}{|l|}{ IPT/Fansidar* } \\
\hline Yes & $386(90.8)$ & $58(93.5)$ & $0.68(0.24-1.98)$ & 0.634 \\
\hline No & $39(9.2)$ & $4(6.5)$ & & \\
\hline \multicolumn{5}{|l|}{ Tetanus toxoid } \\
\hline Yes & $404(95.1)$ & $59(95.2)$ & $0.99(0.28-3.38)$ & 0.970 \\
\hline No & $21(4.9)$ & $3(4.8)$ & & \\
\hline \multicolumn{5}{|l|}{ Complications during pregnancy } \\
\hline No & $175(41.2)$ & $24(38.7)$ & & \\
\hline Yes & $250(58.8)$ & $38(61.3)$ & $1.11(0.64-1.91)$ & 0.710 \\
\hline \multicolumn{5}{|l|}{ Perinatal Factors } \\
\hline \multicolumn{5}{|l|}{ Place of delivery } \\
\hline Hospital & $222(52.2)$ & $23(37.1)$ & & \\
\hline Health Centre, private clinic,etc. (Not hospital) & $203(47.8)$ & $39(62.9)$ & $1.85(1.07-3.21)$ & 0.026 \\
\hline \multicolumn{5}{|l|}{ Mode of delivery } \\
\hline NVD & $363(85.4)$ & $57(91.9)$ & & \\
\hline Breech \& C/S & $62(14.6)$ & $5(8.1)$ & $0.51(0.19-1.33)$ & 0.234 \\
\hline \multicolumn{5}{|l|}{ Duration of labour } \\
\hline$<24 \mathrm{~h}$ & $323(76.0)$ & $49(79.0)$ & $0.84(0.43-1.61)$ & 0.599 \\
\hline$>24 h$ & $102(24.0)$ & $13(21.0)$ & & \\
\hline \multicolumn{5}{|l|}{ Perinatal complications } \\
\hline None & $389(91.5)$ & $59(95.2)$ & $0.55(0.16-1.84)$ & 0.454 \\
\hline Yes & $36(8.5)$ & $3(4.8)$ & & \\
\hline \multicolumn{5}{|l|}{ Neonatal and post-neonatal characteristics } \\
\hline \multicolumn{5}{|l|}{ Sex of Baby } \\
\hline Male & $218(51.3)$ & $32(51.6)$ & $0.99(0.58-1.68)$ & 0.963 \\
\hline Female & $207(48.7)$ & $30(48.4)$ & & \\
\hline \multicolumn{5}{|l|}{ Birth weight } \\
\hline$\geq 2.5 \mathrm{~kg}$ & $350(95.6)$ & $46(90.2)$ & 1 & \\
\hline$<2.5 \mathrm{~kg}$ & $16(4.4)$ & $5(9.8)$ & $2.38(0.83-6.79)$ & 0.190 \\
\hline Unknown & $59(13.9)$ & $11(17.7)$ & $1.42(0.69-2.89)$ & \\
\hline \multicolumn{5}{|l|}{ Cried at birth } \\
\hline Yes & $374(94.7)$ & $49(79.0)$ & & \\
\hline No & $21(5.3)$ & $9(15.5)$ & $3.27(1.42-7.50)$ & 0.025 \\
\hline Unknown & $30(7.1)$ & $4(6.5)$ & & \\
\hline \multicolumn{5}{|l|}{ Home visit after delivery } \\
\hline Yes & $136(32.0)$ & $20(32.3)$ & $1.01(0.57-1.79)$ & 0.968 \\
\hline No & $289(68.0)$ & $42(67.7)$ & & \\
\hline \multicolumn{5}{|l|}{ Immediate breast feeding at birth } \\
\hline No & $100(23.5)$ & $12(19.4)$ & $1.28(0.66-2.50)$ & 0.466 \\
\hline Yes & $325(76.5)$ & $50(80.6)$ & & \\
\hline
\end{tabular}


Table 3 Distribution of neurodevelopmental disability by antenatal, delivery, and neonatal characteristics, among infants in IgangaMayuge HDSS (Continued)

\begin{tabular}{|c|c|c|c|c|}
\hline Characteristics & Infants without NDD & Infants with NDD & COR $(95 \% \mathrm{Cl})$ & $p$-value \\
\hline \multicolumn{5}{|c|}{ Exclusive Breast feeding } \\
\hline Yes & $105(24.8)$ & $12(19.4)$ & & \\
\hline No & $320(75.2)$ & $50(80.7)$ & $1.37(0.70-2.67)$ & 0.352 \\
\hline \multicolumn{5}{|c|}{ Neonatal danger signs } \\
\hline None & $211(49.6)$ & $28(45.2)$ & & \\
\hline Yes & $214(50.3)$ & $34(54.8)$ & $1.19(0.70-2.04)$ & 0.509 \\
\hline \multicolumn{5}{|c|}{ Post-neonatal complications } \\
\hline None & $64(15.1)$ & $3(4.8)$ & & \\
\hline Yes & $322(75.7)$ & $54(87.1)$ & $3.58(1.10-11.80)$ & 0.036 \\
\hline Don't know & $39(9.2)$ & $5(8.1)$ & $2.73(0.60-12.10)$ & \\
\hline \multicolumn{5}{|c|}{ Number of times the baby fell sick since birth } \\
\hline$<4$ & $182(42.8)$ & $15(24.2)$ & & \\
\hline $4+$ & $231(54.4)$ & $45(72.6)$ & $2.36(1.28-4.38)$ & 0.006 \\
\hline Unknown & $12(2.8)$ & $2(3.2)$ & $2.02(0.41-9.88)$ & \\
\hline \multicolumn{5}{|c|}{ Admission to facility } \\
\hline No & $313(73.6)$ & $44(71.0)$ & & \\
\hline Admitted & $112(26.4)$ & $18(29.0)$ & $1.14(0.63-2.06)$ & 0.656 \\
\hline
\end{tabular}

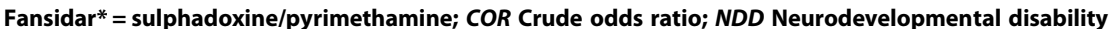

Table 4 Multivariate logistic regression of key variables associated with Neuro-developmental disability among infants in Iganga/ Mayuge HDSS

\begin{tabular}{|c|c|c|c|}
\hline Covariate & & COR $(95 \% \mathrm{Cl})$ & AOR $(95 \% \mathrm{Cl})$ \\
\hline \multirow[t]{2}{*}{ Mode of delivery } & Normal & 1 & \\
\hline & Caesarean/breech & $0.51(0.19-1.33)$ & $0.20(0.04-1.09)^{*}$ \\
\hline \multirow[t]{2}{*}{ Maternal education } & O Level and below & 1 & 1 \\
\hline & A Level \& above & $0.39(0.09-1.69)$ & $0.58(0.12-2.73)$ \\
\hline \multirow[t]{3}{*}{ Father's occupation } & Salaried & 1 & 1 \\
\hline & Business & $2.01(0.87-4.62)$ & $2.03(0.82-5.07)$ \\
\hline & Others & $1.01(0.43-2.33)$ & $0.90(0.36-2.24)$ \\
\hline \multirow[t]{2}{*}{ Mother's parity } & $1-3$ & 1 & 1 \\
\hline & $4+$ & $1.88(1.10-3.23)^{* *}$ & $1.81(1.03-3.19)^{* *}$ \\
\hline \multirow[t]{3}{*}{ Cried at birth } & Yes & 1 & 1 \\
\hline & No & $3.27(1.42-7.54)^{* *}$ & $3.66(1.46-9.17)^{* * *}$ \\
\hline & Don't know & $1.02(0.34-3.01)$ & $4.02(0.59-27.47)$ \\
\hline \multirow[t]{2}{*}{ Exclusive breast feeding for six months } & Yes & 1 & 1 \\
\hline & No (Gave other feeds) & $1.37(0.70-2.67)$ & $0.62(0.30-1.27)$ \\
\hline \multirow[t]{3}{*}{ Post-neonatal complications } & No & 1 & 1 \\
\hline & Yes & $3.58(1.10-11.80)^{* *}$ & $4.15(1.22-14.11)^{* *}$ \\
\hline & Don't know & $2.73(0.60-12.10)$ & $2.42(0.52-11.31)$ \\
\hline \multirow[t]{3}{*}{ Weight at birth } & $<2.5 \mathrm{~kg}$ & $2.37(0.83-6.79)$ & $2.54(0.79-8.12)$ \\
\hline & $2.5+\mathrm{kg}$ & 1 & 1 \\
\hline & Unknown & $1.42(0.69-2.89)$ & $1.27(0.59-2.72)$ \\
\hline
\end{tabular}

$N=484 ;$ LR chi2 [12] $=34.84, P$-value $<0.0005$

${ }^{*} p<0.1,{ }^{* *} P<0.05,{ }^{* * *} P<0.001$, COR Crude odds ratio, AOR Adjusted odds ratio 
birth may be considered biological factors, there could also be an environmental component related with challenges in the health systems readiness to offer quality services due to various delays in care seeking. On the other hand, the mother's parity of more than three children is more of an environmental factor, related with social and economic demands on the family, which limit adequate child care and nurturing.

Infants with post-neonatal complications had a higher likelihood of developing neural disability ( $p=$ 0.036). This is in line with what was reported among Ethiopian infants in whom a third of the disabilities occurred after the neonatal period in infancy. Similar to a Nepalese study, [31], complications during the neonatal period were, unexpectedly, not associated with disability possibly due to high neonatal mortality of vulnerable newborns in Uganda [17]. Failure to cry at birth which points to intrapartum complications highlights challenges in quality of delivery/birth care services. Maulik and Darmstadt [27] argue that most developmental disabilities are preventable if quality health services are given promptly during the prenatal, natal, and postnatal period. Although there has been an improvement in institutional deliveries in Uganda from 38\% in 2006 to $73 \%$ in 2016, maternal and neonatal outcomes have not changed much which might be an indication of limitations in quality of service provision [17, 32]. In a bid to address the poor neonatal outcomes, the Ministry of Health in Uganda, through its strategic plan is scaling up basic neonatal care services at Primary Health Care centres and comprehensive neonatal care at higher level health centres and district hospitals nationwide. In addition, there are plans for provision of intensive neonatal care at regional level [33]. As a result, more newborns will be saved; however, if the quality of services is not put into consideration, the rate of NDD among survivors is likely to increase [34]. Therefore, this calls for vigilance in strengthening quality of care services while improving access, not only during the intrapartum and neonatal period but also throughout infancy.

Unexpectedly, LBW was not found to be associated with NDD in our study. However, we had limited power to indicate an association due to limited number of LBW babies in our sample which could be due to survival bias. Similar results were found in a study of the prevalence of cerebral palsy in Uganda by KakoozaMwesige et al., [29]; and by other researchers in countries with high neonatal mortality $[11,31]$. On the other hand, a systematic review by Mwaniki et al., 2013, found neonatal insults (prematurity, neonatal infections, and others) as significant risk factors for long-term NDDs [35]. These findings call for further prospective longitudinal studies.
In the current study we found an association between mothers' parity and presence of NDD which could be due to challenges in social-interactive caregiving practices. Similar findings were reported by a study from Kenya [11] where parents having more than five children was significantly associated with neurological impairment. Parents/caregivers with many children may be less likely to give the desired attention, support and stimulation of their children hence the high disability in social behaviour domain in the current study. Socio-emotional development is important in control of one's feelings, building relationships with others, and ability to explore and learn about the surroundings [10]. This kind of development which starts right after birth is nurtured through daily interactions with parents and other people around the children $[10,36]$. Thus, parents and families need more support on how to effectively interact with their infants/children, in the course of daily care, to foster socio-emotional development [37]. In Uganda, the extended family system, often polygamous, with several children in the household, limits parent-child interaction. While there is a policy framework for early child development [20] little has been done in terms of implementation especially for the younger pre-school children. Innovative programs are needed to educate parents and families (focusing on those with many children) on how to stimulate infants in order to optimise their socio-emotional development. In the health sector, the high utilisation of antenatal care and immunisation coupled with the availability of CHWs/VHTs provide an opportunity for integration of responsive care giving programs.

\section{Methodological considerations}

There are a few methodological concerns in the current study. One of them is the young age group (9 to 12 months) assessed yet some disabilities may manifest later and minor disabilities may eventually change with time, especially, if addressed [28]. In addition we did not collect data to enable categorization of participants by wealth quintiles. We used the father's occupation as proxy, which could have limited the association found compared with other studies $[9,11,38]$. In addition, the domain of Social function of the MDAT tool has some items linked to personal care, which may partially explain the findings in that domain. None the less, our results have highlighted the high prevalence of NDD, the categories of disability and the need to address it as early as possible during infancy. We further argue for the need to conduct prospective longitudinal studies of preterm babies to understand their outcomes better; the mortality and their morbidities including the NDD in Uganda and other countries with similar settings in order to design contextually appropriate interventions to 
prevent NDD or support infants who are affected by NDD.

\section{Conclusion}

The study has revealed a high NDD prevalence especially in the social domain. The key factors associated with NDD are: failure to cry at birth, post-neonatal complications and mother's parity of more than three children. Failure of a baby to cry at birth is a proxy for challenges in the quality of perinatal service provision and efforts should be made to address this as a priority area in order to minimize the risk of disability.

The post-neonatal complications suggest limited access as well as low quality service provision in the postnatal period. In resource limited settings, having a high number of children poses challenges in parent-child interaction. This calls for integration of innovative strategies in existing VHT/CHW programmes, and in ANC and immunization clinics to improve awareness of parents on opportunities for effective stimulation, child encouragement and regulation during daily nurturing to enable optimal neurodevelopment.

\section{Abbreviations \\ ANC: Antenatal Care; CHW: Community Health Worker; GA: Gestational Age; HDSS: Health Demographic Surveillance Site; LBW: Low Birth Weight; LICs: Low Income Countries; LMIC: Low and Middle Income Countries; LNMP: Last normal Menstrual Period; MDAT: Malawi Developmental Assessment Tool; NDD: Neurodevelopmental Disability; VHT: Village Health Team}

\section{Acknowledgements}

We express our gratitude to the leadership of Iganga/Mayuge HDSS for all the support rendered during data collection, and the research assistants who collected data used in this study. We are also thankful to the families which participated in this study.

\section{Ethical approval and consent to participate}

This study was approved by the Makerere University School of Health Sciences Research and Ethics Committee (SHSREC Ref: 2017-011), and the Uganda National Council of Science and Technology (Ref. SS4600). Written informed consent was obtained from all study participants.

\section{Sources of funding}

This work was funded under Makerere-SIDA research programme (Project Sida-344), which is greatly appreciated. In addition, we are grateful to the Saving Brains of Grand Challenges Canada whose grant enabled the initial concept development of this study.

The funding bodies did not play any direct role in design of the study, collection, analysis, and interpretation of data, and writing of the manuscript. The content is solely the responsibility of the authors.

\section{Authors' contributions}

GN conceptualized, drafted and led the writing of the manuscript. JKT, PW and $\mathrm{HH}$ provided overall conceptual guidance of the study and writing of the manuscript. PM and GN acquired and analysed the data. $\mathrm{HH}, \mathrm{CH}, \mathrm{CN}, \mathrm{MN}$ and AKM contributed to interpretation of data and to the writing of the manuscript. All authors reviewed and approved the final version of the manuscript.

\section{Availability of data and materials}

The datasets used and/or analysed during the current study are available from the corresponding author on reasonable request.
Consent for publication

Not applicable.

\section{Competing interests}

All authors declare no conflict of interest.

\section{Author details}

${ }^{1}$ Makerere University School of Public Health, College of Health Sciences, Mulago Hill Road, P. O. Box, 7072 Kampala, Uganda. ${ }^{2}$ Global Health-Health Systems \& Policy, Public Health Sciences, Karolinska Institutet, Stockholm, Sweden. ${ }^{3}$ Astrid Lindgren Children's Hospital, Karolinska University Hospital, Stockholm, Sweden. ${ }^{4}$ Department of Disease Control, London School of Hygiene and Tropical Medicine, London, England. ${ }^{5} \mathrm{MRC} /$ Uganda Virus Research Institute \& LSHTM Research Unit, Entebbe, Uganda. ${ }^{6}$ Department of Paediatrics and Child Health, School of Medicine, College of Health Sciences, Makerere University, Kampala, Uganda.

Received: 4 January 2019 Accepted: 7 October 2019

Published online: 24 October 2019

\section{References}

1. Lawn JE, Kinney MV, Black RE, Pitt C, Cousens S, Kerber K, et al. Newborn survival: a multi-country analysis of a decade of change. Health policy and planning. 2012;27(suppl_3):iii6-iii28.

2. Blencowe H, Lee AC, Cousens S, Bahalim A, Narwal R, Zhong N, et al. Preterm birth-associated neurodevelopmental impairment estimates at regional and global levels for 2010. Pediatr Res. 2013;74(S1):17.

3. UN-IGME. Levels and Trends in Child Mortality: Report 2018, Estimates developed by the UN Inter-agency Group for Child Mortality Estimation. http://www.childmortality.org/. 2018.

4. Blencowe H, Vos T, Lee AC, Philips R, Lozano R, Alvarado MR, et al. Estimates of neonatal morbidities and disabilities at regional and global levels for 2010: introduction, methods overview, and relevant findings from the global burden of disease study. Pediatr Res. 2013;74(S1):4.

5. Grantham-McGregor S, Cheung YB, Cueto S, Glewwe P, Ritcher L, Strupp B. Child development in developing countries 1: developmental potentials in developing countries for children in the first five years. Lancet. 2007:369:60-70.

6. UNICEF. Monitoring child disability in developing countries results from the multiple Indicator cluster surveys. New York: UNICEF, 2008 [accessed on August 24, 2016].

7. Goldstein S, Reynolds CR. Handbook of neurodevelopmental and genetic disorders in children, 2/e: Guilford press; 2010.

8. Bronfenbrenner U. The ecology of human development: experiments by design and nature. Cambridge, MA: Harvard University Press; 1979. p. 365-9.

9. Walker SP, Wachs TD, Gardner JM, Lozoff B, Wasserman GA, Pollitt E, et al. Child development: risk factors for adverse outcomes in developing countries. Lancet. 2007;369(9556):145-57.

10. Morris AS, Silk JS, Steinberg L, Myers SS, Robinson LR. The role of the family context in the development of emotion regulation. Soc Dev. 2007;16(2): 361-88.

11. Kawakatsu Y, Kaneko S, Karama M, Honda S. Prevalence and risk factors of neurological impairment among children aged 6-9 years: from population based cross sectional study in western Kenya. BMC Pediatr. 2012;12(1):186.

12. Abubakar A, Holding P, Van de Vijver FJ, Newton C, Van Baar A. Children at risk for developmental delay can be recognised by stunting, being underweight, ill health, little maternal schooling or high gravidity. J Child Psychol Psychiatry. 2010;51(6):652-9.

13. Bhutani VK, Zipursky A, Blencowe H, Khanna R, Sgro M, Ebbesen F, et al. Neonatal hyperbilirubinemia and rhesus disease of the newborn: incidence and impairment estimates for 2010 at regional and global levels. Pediatr Res. 2013;74(S1):86.

14. Lee AC, Kozuki N, Blencowe H, Vos T, Bahalim A, Darmstadt GL, et al. Intrapartum-related neonatal encephalopathy incidence and impairment at regional and global levels for 2010 with trends from 1990. Pediatr Res. 2013; 74(S1):50.

15. Seale AC, Blencowe $H$, Zaidi A, Ganatra $H$, Syed $S$, Engmann $C$, et al. Neonatal severe bacterial infection impairment estimates in 
South Asia, sub-Saharan Africa, and Latin America for 2010. Pediatr Res. 2013;74(S1):73.

16. Waiswa P, Kallander K, Peterson S, Tomson G, Pariyo GW. Using the three delays model to understand why newborn babies die in eastern Uganda. Tropical Med Int Health. 2010;15(8):964-72.

17. UBOS. Uganda Demographic And Health Survey 2016. Calverton, Maryland, USA: U. B O S U A M Orc, 2016

18. Miller S, Abalos E, Chamillard M, Ciapponi A, Colaci D, Comandé D, et al. Beyond too little, too late and too much, too soon: a pathway towards evidence-based, respectful maternity care worldwide. Lancet. 2016; 388(10056):2176-92

19. Namazzi G, Okuga M, Tetui M, Muhumuza Kananura R, Kakaire A, Namutamba S, et al. Working with community health workers to improve maternal and newborn health outcomes: implementation and scale-up lessons from eastern Uganda. Global health action. 2017; 10(sup4):1345495

20. MoGLSD. The National Integrated Early Childhood Development Policy Action Plan (2016-2021) of Uganda. In: Ministry of Gender LaSD, editor. Kampala2016.

21. Boydell N, Nalukenge W, Siu G, Seeley J, Wight D. How mothers in poverty explain their use of corporal punishment: a qualitative study in Kampala, Uganda. Eur J Dev Res. 2017;29(5):999-1016.

22. MUCHAP. Annual Progress Report, 2015: Makerere University Centre for Health \& Population Research (MUCHAP) operating Iganga-M HDSS-Uganda (IMHDSS). Makerere University 2016.

23. Gladstone M, Lancaster GA, Umar E, Nyirenda M, Kayira E, van den Broek NR, et al. The Malawi developmental assessment tool (MDAT): the creation, validation, and reliability of a tool to assess child development in rural African settings. PLoS Med. 2010;7(5):e1000273.

24. Cole TJ, Freeman JV, Preece MA. British 1990 growth reference centiles for weight, height, body mass index and head circumference fitted by maximum penalized likelihood. Stat Med. 1998;17(4):407-29.

25. Olusanya BO, Davis AC, Wertlieb D, Boo N-Y, Nair M, Halpern R, et al. Developmental disabilities among children younger than 5 years in 195 countries and territories, 1990-2016: a systematic analysis for the Global Burden of Disease Study 2016. Lancet Glob Health 2018.

26. Geda B, Berhane Y, Assefa N, Worku A. In rural eastern Ethiopia hearing loss is the most frequent disability during childhood: a community based survey. PLoS One. 2016;11(5):e0152791.

27. Maulik PK, Darmstadt GL. Childhood disability in low-and middle-income countries: overview of screening, prevention, services, legislation, and epidemiology. Pediatrics. 2007;120(Supplement 1):S1-S55.

28. Bornstein $\mathrm{MH}$, Hendricks C. Screening for developmental disabilities in developing countries. Soc Sci Med. 2013;97:307-15.

29. Kakooza-Mwesige A, Andrews C, Peterson S, Mangen FW, Eliasson AC, Forssberg $\mathrm{H}$. Prevalence of cerebral palsy in Uganda: a population-based study. Lancet Glob Health. 2017;5(12):e1275-e82.

30. Mung'ala-Odera V, Meehan R, Njuguna P. Mturi N, Alcock KJ, Newton C Prevalence and risk factors of neurological disability and impairment in children living in rural Kenya. Int J Epidemiol. 2006;35(3):683-8.

31. Haworth EJ, Tumbahangphe KM, Costello A, Manandhar D, Adhikari D, Budhathoki $\mathrm{B}$, et al. Prenatal and perinatal risk factors for disability in a rural Nepali birth cohort. BMJ Glob Health. 2017;2(3):e000312.

32. Hanson C, Manzi F, Mkumbo E, Shirima K, Penfold S, Hill Z, et al. Effectiveness of a home-based counselling strategy on neonatal care and survival: a cluster-randomised trial in six districts of rural southern Tanzania. PLoS Med. 2015;12(9):e1001881.

33. MOH. Investment Case for Reproductive, Maternal, Newborn and Child Health Sharpened Plan for Uganda. In: health R, editor. 2016.

34. Lawn JE, Blencowe H, Darmstadt GL, Bhutta ZA. Beyond newborn survival: the world you are born into determines your risk of disability-free survival: Nature Publishing Group; 2013

35. Mwaniki MK, Atieno M, Lawn JE, Newton CR. Long-term neurodevelopmental outcomes after intrauterine and neonatal insults: a systematic review. Lancet. 2012;379(9814):445-52.

36. Maulik P, Darmstadt G. Community-based interventions to optimize early childhood development in low resource settings. J Perinatol. 2009; 29(8):531.

37. Morris J, Jones L, Berrino A, Jordans MJ, Okema L, Crow C. Does combining infant stimulation with emergency feeding improve psychosocial outcomes for displaced mothers and babies? A controlled evaluation from northern Uganda. Am J Orthopsychiatry. 2012;82(3):349-57.

38. UBOS. Uganda demographic and health survey 2011. Maryland, USA: U. B O. S. U. A. M. Orc. Calverton; 2011.

\section{Publisher's Note}

Springer Nature remains neutral with regard to jurisdictional claims in published maps and institutional affiliations.

\section{Ready to submit your research? Choose BMC and benefit from:}

- fast, convenient online submission

- thorough peer review by experienced researchers in your field

- rapid publication on acceptance

- support for research data, including large and complex data types

- gold Open Access which fosters wider collaboration and increased citations

- maximum visibility for your research: over $100 \mathrm{M}$ website views per year

At $\mathrm{BMC}$, research is always in progress.

Learn more biomedcentral.com/submissions 